\title{
ATTENUATION OF SEISMIC WAVES IN THE LITHOSPHERE OF THE NORTHERN PART OF THE BASIN AND RANGE PROVINCE
}

\section{A. A. Dobrynina}

\author{
Institute of the Earth's Crust, SB RAS, Irkutsk, Russia
}

\begin{abstract}
This paper presents results of the study of attenuation of seismic waves in the lithosphere and upper mantle of the northern part of the Basin and Range Province (BRP) (Fig. 1). In this study, the coda-wave method [Aki, Chouet, 1975] is applied to process data collected in the seismic experiment conducted in 1988-1989, PASSCAL Basin and Range Passive Seismic Experiment [Owens, Randall, 1989], including records of 66 earthquakes and explosions $\left(M_{\mathrm{b}}=1.1-5.0\right)$ which occurred in BRP (Fig. 2).

The effective seismic quality factor by the coda is calculated using the single-backscattering model [Aki, Chouet, 1975]. The $Q_{\mathrm{C}}$ values are calculated for 18 values of the lapse time window $W$ from 10 to $95 \mathrm{sec}$ with the step of 5 sec at six (6) central frequencies $(0.3,0.75,1.5,3.0,6.0$, and $12.0 \mathrm{~Hz})$. In total, 7776 individual measurements of $Q_{\mathrm{C}}$ were done. It is observed that the quality factor $Q_{\mathrm{C}}$ is strongly dependent on the frequency and the lapse time window $W: Q_{\mathrm{C}}$ increases from $12 \pm 6$ to $359 \pm 17$ for the central frequencies of 0.3 and $12.0 \mathrm{~Hz}$ when the lapse time window is $W=10$ sec and from $87 \pm 6$ to $1177 \pm 87$ for the same frequencies when $W=95$ sec (Fig. 6). On the basis of the $Q_{C}$ values obtained for all the lapse time windows $W$ empirical relationships of quality factors and frequencies are calculated according to [Mitchell, 1981], and values of quality factor $Q_{0}$ at reference frequency $f_{0}\left(f_{0}=1 \mathrm{~Hz}\right)$ and frequency parameter $n$ (which is close to 1 and varies depending on the heterogeneity of the medium [Aki, 1981]) are obtained. In this study, $Q_{0}$ varies from $60 \pm 8$ to $222 \pm 17$, the frequency parameter ranges from $0.57 \pm 0.04$ to $0.84 \pm 0.05$, and the attenuation coefficient $\delta$ varies from 0.015 to $0.004 \mathrm{~km}^{-1}$, depending on $W$ (Fig. 8); similar values of attenuation parameters are typical of regions with high tectonic activity [Mak et al., 2004].
\end{abstract}

In the single-backscattering model, the dependence of the attenuation parameters from the lapse time window can be explained in terms of the depth of formation of the coda [Pulli, 1984]: a larger value of $W$ corresponds to a greater depth through which the coda-waves go. As shown by the analysis of variations of attenuation coefficient $\delta$ and frequency parameter $n$ for the Basin and Range Province, both parameters decrease irregularly with depth - the slope of the curve showing variations of $\delta$ is considerably changed at the depth of $150 \mathrm{~km}$. At the top of the graph (to the depth of $150 \mathrm{~km}$ ), an abrupt change of $\delta$ with depth is observed; it is clearly seen in the graph of gradient $\delta$ (Fig. 9 and Fig. 10); such behaviour is also characteristic of $n$. At the depth of $140 \mathrm{~km}$, parameter $n$ is increased. In the middle section (at depths of 150-200 km), the slope of the $\delta$ curve increases, and gradients of $\delta$ and the frequency parameter are significantly reduced. At the bottom of the profile (> $200 \mathrm{~km}$ ), the value of $\delta$ is almost constant, and an abrupt increase of $n$ is observed (Fig. 9 and Fig. 10). Figure 10 shows the high-speed profile of the area under study, which is published in [Wagner et al., 2012]. The profile shows the low velocity mantle under the Basin and Range Province, actually starting underneath the Moho (at the depth of 50-60 km). The lower boundary of the low-velocity mantle is located at the depth of $130-160 \mathrm{~km}$. Thus, there are grounds to conclude that the change in the slope of the curve showing dependence of $\delta$ from the depth is related to the deep structure of the medium. The abrupt changes of $\delta$ and $n$ are associated with the velocity discontinuities of the medium. The high values of $\delta$ and $n$, which are characteristic of the upper part of the profile, indicate the high degree of heterogeneity of the medium, which is also confirmed by the low velocities of seismic waves in the area under study [Wagner et al., 2012]. The reduction of parameters $\delta$ and $n$ in the middle and lower parts of the profile suggests a more homogeneous structure of the medium at larger depths.

As a result of the study of the characteristics of seismic wave's attenuation in the lithosphere and the upper mantle of the northern part of the Basin and Range Province, it is established that the effective seismic quality factor $Q_{\mathrm{C}}$ is highly dependent on the frequency in the range of $0.5-16.0 \mathrm{~Hz}$. The empirical relationships of $Q(f)$ for various lapse time windows are obtained; it is shown that increasing the lapse time window causes the values of the effective seismic quality factor to increase, which may be interpreted as reduction of attenuation with depth. By comparing the depth variations of the attenuation coefficient and the frequency parameter against the velocity structure, it is shown that there is a distinct change in attenuation of seismic waves at the velocity discontinuities in the northern part of the Basin and Range Province. 
Recommended by S.I. Sherman

Citation: Dobrynina A.A. 2013. Attenuation of seismic waves in the lithosphere of the northern part of the Basin and Range Province. Geodynamics \& Tectonophysics 4 (1), 53-67. doi:10.5800/GT-2013-4-1-0091.

\title{
ЗАТУХАНИЕ СЕЙСМИЧЕСКИХ ВОЛН В ЛИТОСФЕРЕ СЕВЕРНОЙ ЧАСТИ ПРОВИНЦИИ БАССЕЙНОВ И ХРЕБТОВ
}

\section{А. А. Добрынина}

\author{
Институт земной коры СО РАН, Иркутск, Россия
}

Аннотация: В настоящей работе представлены результаты исследования затухания сейсмических волн методом кодаволн [Aki, Chouet, 1975] в литосфере и верхней мантии северной части Провинции Бассейнов и Хребтов (ПБХ) (рис. 1). В работе использовались данные, полученные в рамках сейсмического эксперимента 1988-1989 PASSCAL Basin and Range Passive Seismic Experiment [Owens, Randall, 1989], - записи 66 землетрясений и взрывов с магнитудами $M_{\mathrm{b}}=1.1-5.0$, произошедших на территории ПБХ (рис. 2).

Для расчета эффективной сейсмической добротности по коде использовалась модель однократного рассеяния [Aki, Chouet, 1975]. Расчет значений $Q_{\mathrm{C}}$ выполнялся для 18 значений длины окна обработки коды $W$ - от 10 до 95 с с шагом 5 с на 6 центральных частотах $f: 0.3,0.75,1.5,3.0,6.0$ и 12.0 Гц. Всего выполнено 7776 индивидуальных измерений $Q_{\mathrm{C}}$. Наблюдается сильная зависимость добротности от частоты и длины окна обработки коды: $Q_{\mathrm{C}}$ возрастает от $12 \pm 6$ до $359 \pm 17$ для центральных частот 0.3 и 12.0 Гц при длине окна обработки коды $W=10$ с и от $87 \pm 6$ до $1177 \pm 87$ на тех же частотах при $W=95$ с (рис. 6). На базе полученных значений $Q_{C}$ для всех значений длины окна $W$ были рассчитаны эмпирические зависимости добротности от частоты согласно [Mitchell, 1981] и получены значения: $Q_{0}$ - добротность на референтной частоте $f_{0}\left(f_{0}=1\right.$ Гц) и $n$ - частотный параметр ( $n$ близок к 1 и меняется в зависимости от неоднородности среды [Aki, 1981]). Полученные в настоящей работе значения $Q_{0}$ меняются от $60 \pm 8$ до $222 \pm 17$, значения частотного параметра варьируются от $0.57 \pm 0.04$ до $0.84 \pm 0.05$, и коэффициент затухания $\delta$ меняется в пределах 0.015-0.004 км ${ }^{-1}$ в зависимости от $W$ (рис. 8), подобные значения параметров затухания характерны для районов с высокой тектонической активностью [Mak et al., 2004].

В рамках модели однократного рассеяния зависимость параметров затухания от длины окна обработки коды может быть объяснена с позиций глубины формирования коды [Pulli, 1984]: большее значение $W$ соответствует большей глубине прохождения кода-волн. Анализ вариаций коэффициента затухания $\delta$ и частотного параметра $n$ для Провинции Бассейнов и Хребтов показал, что оба параметра неравномерно уменьшаются с увеличением глубины на глубине 150 км наклон графика изменения $\delta$ заметно меняется. В верхней части графика (глубины до 150 км) наблюдается резкое изменение $\delta$ с глубиной, особенно хорошо это видно на графике градиента $\delta$ (рис. 9, 10), подобное поведение характерно и для $n$. Также на глубине около 140 км отмечается скачок параметра $n$. В средней части (на глубинах 150-200 км) наклон графика $\delta$ увеличивается, градиенты $\delta$ и частотного параметра значительно уменьшаются. И в нижней части разреза (>200 км) значение $\delta$ становится практически постоянным, также отмечается резкое скачкообразное увеличение значения $n$ (рис. 9, 10). На рисунке приведен скоростной разрез исследуемого региона, полученный в работе [Wagner et al., 2012]. На разрезе видно, что под Провинцией Бассейнов и Хребтов расположена низкоскоростная мантия, начинающаяся практически под границей Мохо (на глубине 50-60 км). Нижняя граница низкоскоростной мантии находится на глубине 130-160 км. Таким образом, можно заключить, что изменение угла наклона графика зависимости $\delta$ от глубины связано с глубинным строением среды. При этом резкие изменения $\delta$ и $n$ приурочены к скоростным границам среды. Высокие значения $\delta$ и $n$, характерные для верхней части разреза, свидетельствуют о высокой степени неоднородности среды, что подтверждается также низкими скоростями сейсмических волн в данной области [Wagner et al., 2012]. Уменьшение параметров $\delta$ и $n$ в средней и нижней частях разреза говорит о более однородной структуре среды на больших глубинах.

В результате проведенного исследования характеристик затухания сейсмических волн в литосфере и верхней мантии северной части Провинции Бассейнов и Хребтов установлена высокая зависимость эффективной сейсмической добротности $Q_{\mathrm{C}}$ от частоты в диапазоне 0.5-16.0 Гц. Получены эмпирические соотношения $Q(f)$ для разной длины окна обработки коды; показано, что значение эффективной сейсмической добротности увеличивается с увеличением длины окна обработки коды, что может быть интерпретировано как уменьшение затухания с глубиной. Сопоставление глубинных вариаций коэффициента затухания и частотного параметра со скоростным строением показало, что для северной части Провинции Бассейнов и Хребтов на скоростных границах наблюдается отчетливое изменение затухания сейсмических волн. 


\section{1. ВВЕДЕНИЕ}

В работе представлены результаты исследования затухания сейсмических волн в литосфере и верхней мантии северной части Провинции Бассейнов и Хребтов. Затуханием сейсмических волн называют уменьшение амплитуды (или энергии) волны при прохождении ее в геологической среде вследствие геометрического расхождения, рассеяния на неоднородностях, потерь на тепло и др. [Aki, Chouet, 1975]. Для описания затухания обычно используется безразмерный параметр $Q$ (добротность), который определяется как отношение энергии волны к энергии, потерянной за один цикл колебания. K настоящему времени разработан ряд методов оценки затухания сейсмических волн, при этом сейсмическая добротность может быть оценена как по прямым волнам (P- и $S$-волны), так и по коде. В представленной работе приведены результаты расчета эффективной сейсмической добротности по кода-волнам $\left(Q_{\mathrm{C}}\right)$ региональных землетрясений и взрывов северной части Провинции Бассейнов и Хребтов. K настоящему времени опубликован ряд работ, посвященных исследованию сейсмической добротности в литосфере Провинции Бассейнов и Хребтов на основе анализа поверхностных Lg-волн $\left(Q_{L g}\right)$ и их коды $\left(Q_{L q}^{\mathrm{C}}\right)$ [Singh, Herrmann, 1983; Chavez, Priestley, 1986; Xie, Mitchell, 1990; Benz et al., 1997; Baqer, Mitchell, 1998; Erickson et al., 2004; Aleqabi, Wysession, 2006]. Но использование различных подходов при определении характеристик затухания делает сопоставление полученных данных с аналогичными параметрами для других регионов затруднительным. Ранее автором с коллегами по кода-волнам местных землетрясений были сделаны оценки эффективной сейсмической добротно-

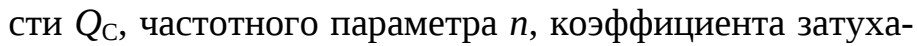
ния $\delta$ и их вариаций с глубиной для Байкальского и Кенийского рифтов [Dobrynina, 2011; Dobrynina et al., $2011,2012]$. Целью настоящего исследования является получение информации о параметрах затухания сейсмических волн в коре и верхней мантии Провинции Бассейнов и Хребтов для дальнейшего сопоставления с аналогичными параметрами других рифтовых систем мира.

\section{2. РЕГИОН ИССЛЕДОВАНИЙ}

Провинция Бассейнов и Хребтов расположена в пределах Северо-Американской литосферной плиты и является типичным представителем континентальных рифтовых систем (рис. 1). Она состоит из системы поднятий и впадин и отличается высокой степенью растяжения литосферы. Исследуемая в настоящей работе область включает в себя северо-западную часть Провинции Бассейнов и Хребтов и центральную часть Сьерра-Невады (рис. 1). Данный район находится в активном тектоническом окружении: с юга-запада рас- положен разлом Сан-Андреас, на востоке и на западе проходят границы сейсмических поясов - Межгорного и Волкер Лейн, через центр проходит ЦентральноНевадский сейсмический пояс [Lee et al., 2009]. Провинция Бассейнов и Хребтов характеризуется высоким уровнем теплового потока [Lay, Wallace, 1988]. Pезультаты геофизических исследований [Bensen et al., 2009; Wagner et al., 2012; Shen et al., 2013] показали, что под Провинцией Бассейнов и Хребтов наблюдается утонение континентальной коры до 30-35 км, а также выявили наличие низкоскоростной верхней мантии $\left(V_{\mathrm{P}} \sim 7.8 \mathrm{KM} / \mathrm{c}\right)$.

\section{3. ДАННЫЕ}

Для оценки параметров затухания использовались данные, полученные в рамках сейсмического эксперимента 1988-1989 PASSCAL Basin and Range Passive Seismic Experiment [Owens, Randall, 1989]. В ходе эксперимента на территории Стилватер Рэйндж (штат Невада, США) с 17 августа 1988 г. по 29 апреля 1989 г. действовала сеть из семи трехкомпонентных среднепериодных сейсмических станций (рис. 2). Для расчета эффективной сейсмической добротности из каталога сейсмических событий были отобраны 66 землетрясений и взрывов с магнитудами $M_{\mathrm{b}}=1.1-5.0\left(M_{\mathrm{b}}-\right.$ магнитуда по объемным волнам), произошедших на территории Провинции Бассейнов и Хребтов (рис. 2). Эпицентральные расстояния варьировались от 10 до 385 км, глубины землетрясений в среднем оцениваются в 3 км [Owens, Randall, 1989]. Использованные в работе данные (записи и каталоги землетрясений) предоставлены IRIS Data Management System (Seattle, Washington, США).

\section{4. МЕТОДЫ И ОБРАБОТКА ДАННЫХ}

Расчет $Q_{C}$ и интерпретация полученных результатов осуществлялись согласно модели однократного рассеяния К. Аки [Aki, Chouet, 1975]. Эта модель рассматривает коду как суперпозицию объемных волн, отраженных от случайно распределенных в среде неоднородностей. Уменьшение амплитуды коды со временем происходит вследствие затухания энергии и геометрического расхождения и не зависит от характеристик очага землетрясения, эффектов пути и усиления на сейсмостанции [Aki, 1969].

Амплитуда коды $A_{\mathrm{C}}$ в момент времени $t$ от времени в очаге для сейсмограммы, отфильтрованной на центральной частоте $f$, связана с добротностью следующим соотношением [Aki, Chouet, 1975]:

$$
A_{C}(f, t)=S(f) \cdot t^{-\gamma} \cdot \exp \left[\frac{-\pi f t}{Q_{C}(f)}\right]
$$




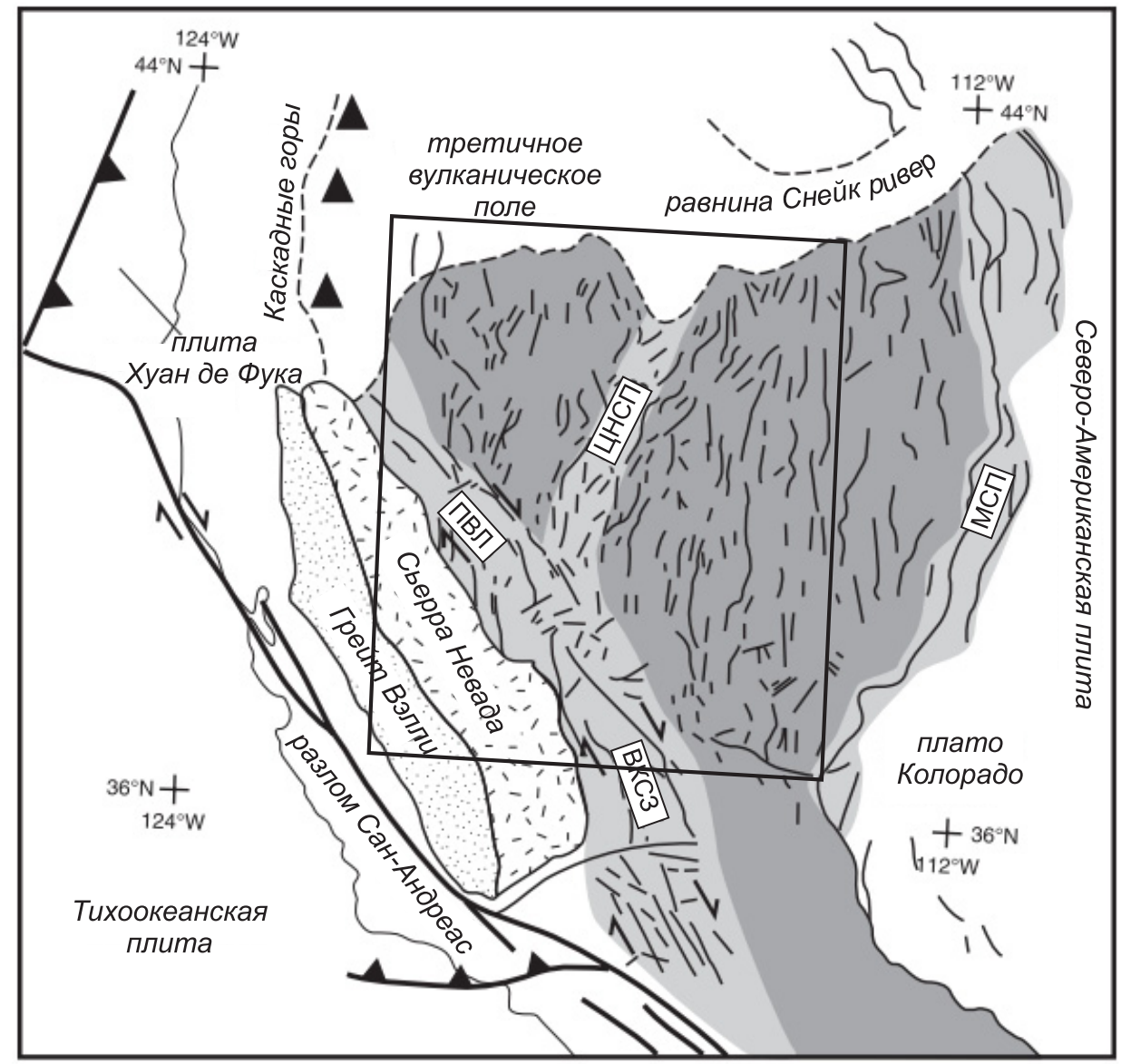

Рис. 1. Схематическая тектоническая карта западной части Кордильер (США), показывающая главные геотектонические провинции и современные границы плит (карта заимствована из работы [Lee et al., 2009]). Темно-серым цветом показана Провинция Бассейнов и Хребтов; светло-серым - ЦНСП (Центрально-Невадский сейсмический пояс), ВКСЗ (Восточно-Калифорнийская сдвиговая зона), МСП (межгорный сейсмический пояс) и ПВЛ (пояс Волкер лейн). Исследуемый в работе регион выделен прямоугольником.

Fig. 1. The schematic tectonic map of the Western Cordillera, USA, showing the main geotectonic provinces and current plate boundaries (from [Lee et al., 2009]). The Basin and Range Province is shown in dark grey; the Central Nevada seismic belt (ЦНСП), the Eastern California Shear Zone (ВКС3), the Intermountain Seismic Zone (МСП), and the Walker Lane Belt (ПВЛ) are shown in light grey. The area under study is marked out by the rectangle.

где ү - характеристика геометрического расхождения, $S(f)$ - временная функция источника. Прологарифмировав (1), получим:

$$
\ln \left(A_{C}(f, t) \cdot t^{\gamma}\right)=\ln (S(f))-\frac{-\pi f t}{Q_{C}(f)}
$$

Геометрическое расхождение задавалось трехсегментной функцией вида (рис. 3):

$$
G(\Delta)= \begin{cases}R_{i j}^{-b 1}, & R_{i j} \leq R_{01} ; \\ R_{01}^{-b 1} \cdot\left(\frac{R_{i j}}{R_{01}}\right)^{-b 2}, & R_{01}<R_{i j} \leq R_{02} ; \\ R_{01}^{-b 1} \cdot\left(\frac{R_{i j}}{R_{01}}\right)^{-b 2} \cdot\left(\frac{R_{i j}}{R_{02}}\right)^{-b 3}, & R_{i j}>R_{02} .\end{cases}
$$

Здесь $R_{\mathrm{ij}} \leq R_{01}-$ для прямых волн, $R_{01}<R_{\mathrm{ij}} \leq R_{02}-$ для волн, отраженных от Мохо, и $R_{\mathrm{ij}}>R_{02}$ - после многократных отражений и преломлений [Burger et al., 1987]. Значения $R_{01}$ и $R_{02}$, как правило, берутся равными 1.5 и 2.5 от глубины Мохо, коэффициенты $b: b 1=1, b 2=0$ и $b 3=0.5$. По данным [Bensen et al., 2009; Shen et al., 2013; and others], граница Мохо под Провинцией Бассейнов и Хребтов проходит на глубине 30-35 км, таким образом, $R_{01}=45-52.5$ и $R_{02}=75-87.5$. Для удобства значения $R_{01}$ и $R_{02}$ брались равными 50 и 90 км, соответственно.

Наклон графика зависимости $\ln \left(A_{C}(f, t) \cdot t^{t}\right)$ от времени $t$ определяет значение $Q$ для рассматриваемой частоты $f$. Согласно [Rautian, Khalturin, 1978], приведенные выше соотношения действительны для времени, большего, чем удвоенное время пробега $S$-волны (рис. 4), так как для этого времени очаговым процессом можно пренебречь. 


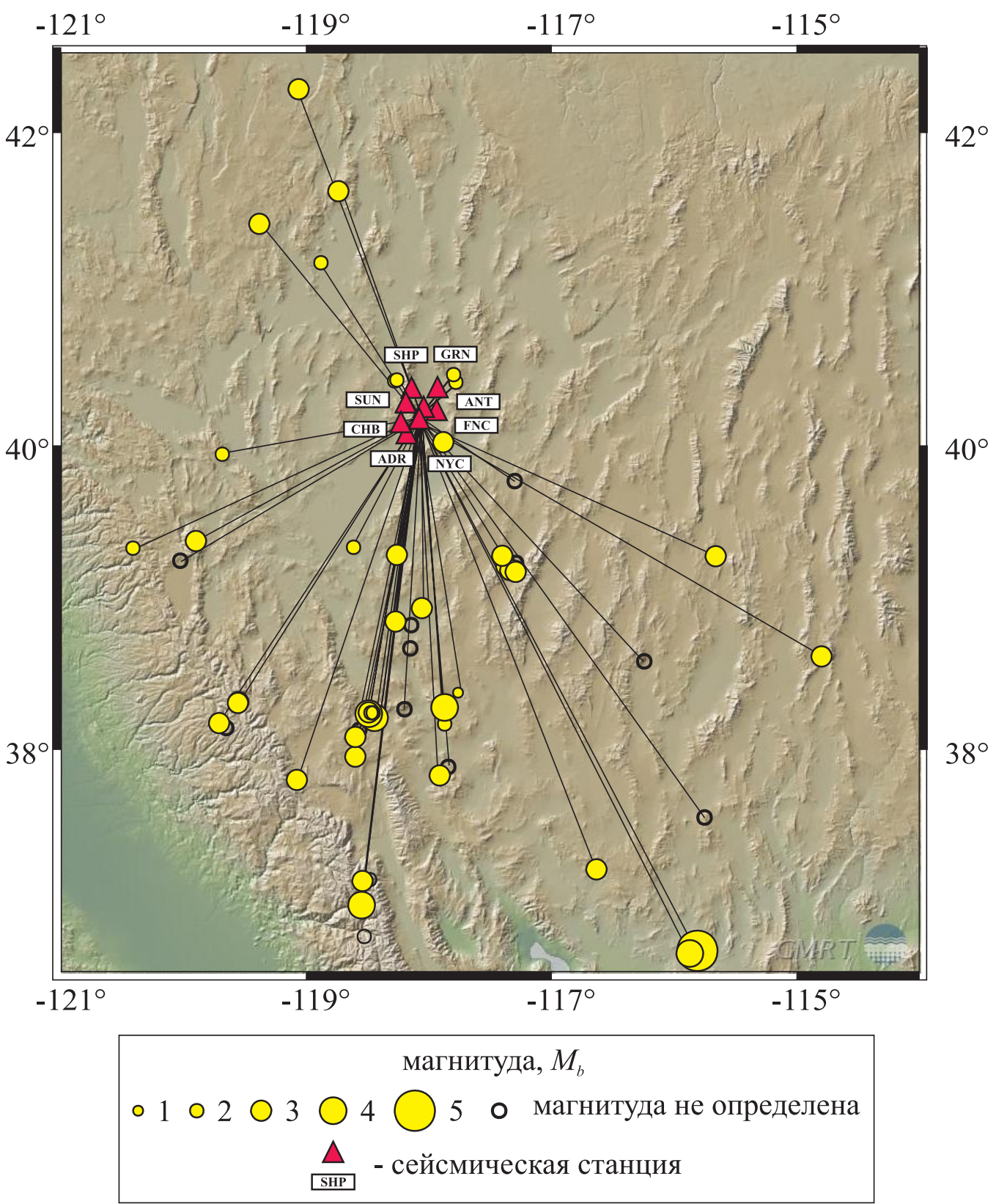

Рис. 2. Положение сейсмических станций и эпицентров землетрясений Провинции Бассейнов и Хребтов, использованных в работе. Прямыми линиями показаны сейсмические трассы «источник - приемник». Цифровой рельеф по данным [Ryan et al., 2009].

Fig. 2. Positions of seismic stations and earthquake epicentres in the Basin and Range Province which are considered in this study. Straight lines show seismic source-receiver traces. The digital terrain is given according to the data published in [Ryan et al., 2009].

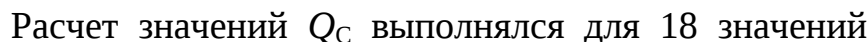
длины окна обработки коды $W$ - от 10 до 95 с с шагом 5 с на 6 центральных частотах $f: 0.3 \pm 0.1,0.75 \pm 0.25$, $1.5 \pm 0.5,3.0 \pm 1.0,6.0 \pm 2.0$ и $12.0 \pm 4.0$ Гц. На рис. 5 при-

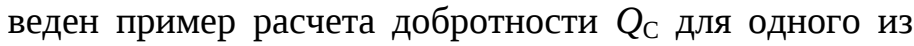
землетрясений Провинции Бассейнов и Хребтов.

\section{5. РЕЗУЛЬТАТЫ И ОБСУЖДЕНИЕ}

Эффективная сейсмическая добротность $Q_{\mathrm{C}}$ литосферы севера Провинции Бассейнов и Хребтов рассчи- тана по записям 66 региональных землетрясений и взрывов, зарегистрированных на семи среднепериодных временных сейсмических станциях, на шести центральных частотах и для восемнадцати временных окон. Всего было выполнено 7776 индивидуальных измерений $Q_{\mathrm{C}}$, при этом в расчетах использовались записи, для которых отношение полезного сигнала к помехе было не менее 3. Для расчета добротности $Q_{\mathrm{C}}$ использовалась программа CodaQ, входящая в состав пакета программ SEISAN [Havskov, Ottemoller, 2003].

Анализ полученных результатов показал четкую зависимость добротности от частоты и длины окна обра- 


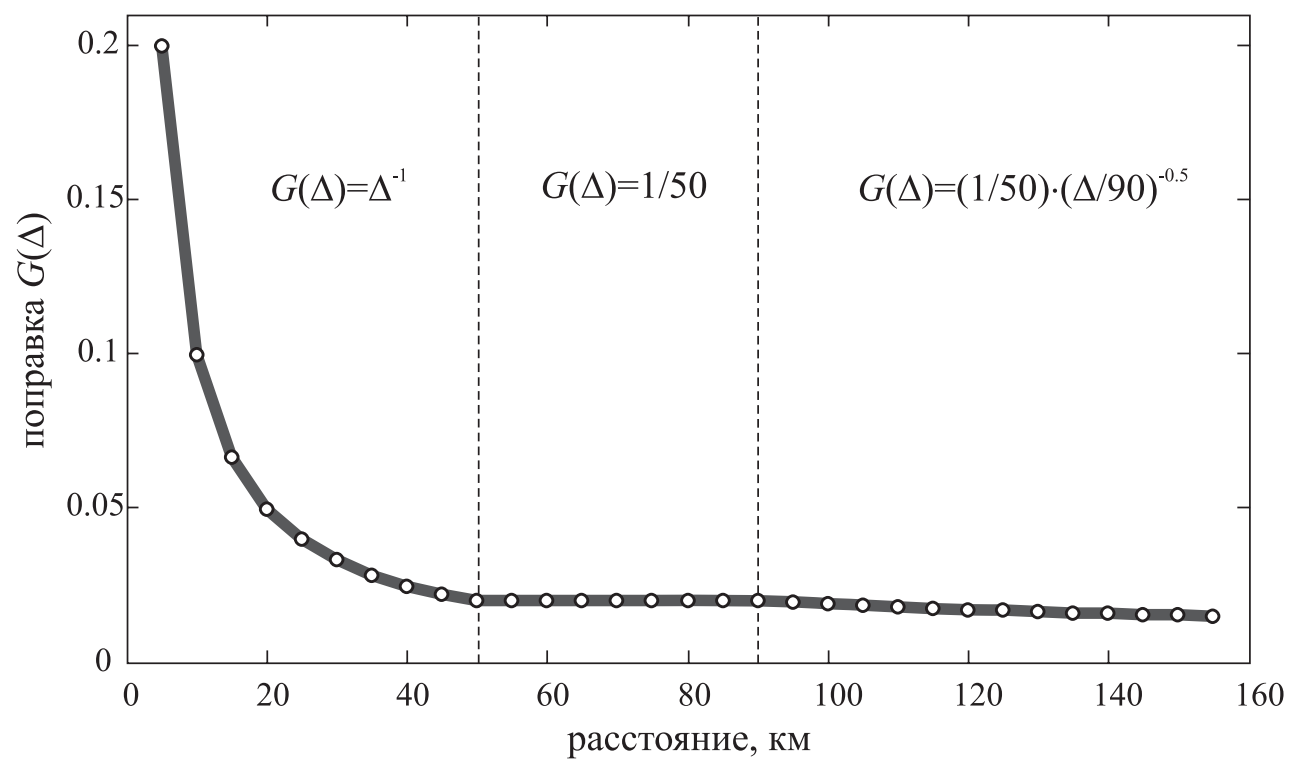

Рис. 3. Вид трехсегментной функции геометрического расхождения $G(\Delta)$ для Провинции Бассейнов и Хребтов (сегменты разделены пунктирными линиями, для каждого сегмента показана формула расчета поправки на геометрическое расхождение).

Fig. 3. The three-segment function of geometrical spreading $G(\Delta)$ for the Basin and Range Province. The segments are separated by dashed lines; equations for calculating the geometrical spreading correction factors are given for every segment under study.

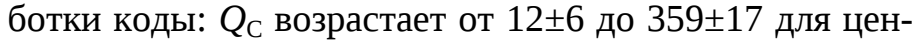
тральных частот 0.3 и 12.0 Гц при длине окна обработки коды $W=10$ с и от $87 \pm 6$ до $1177 \pm 87$ на тех же частотах при $W=95$ с (рис. 6). На базе рассчитанных значений $Q_{\mathrm{C}}$ для всех длин окна $W$ были определены эмпирические зависимости добротности от частоты согласно закону [Mitchell, 1981]:

$$
Q_{C}(f)=Q_{0} \cdot\left(\frac{f}{f_{0}}\right)^{n},
$$

где $Q_{\mathrm{C}}(f)$ - сейсмическая добротность по коде, $Q_{0}-$ добротность на некоторой референтной частоте $f_{0}$ (как правило, $f_{0}=1$ Гц) и $n-$ частотный параметр. Частотный параметр близок к 1 и меняется от региона к ре-

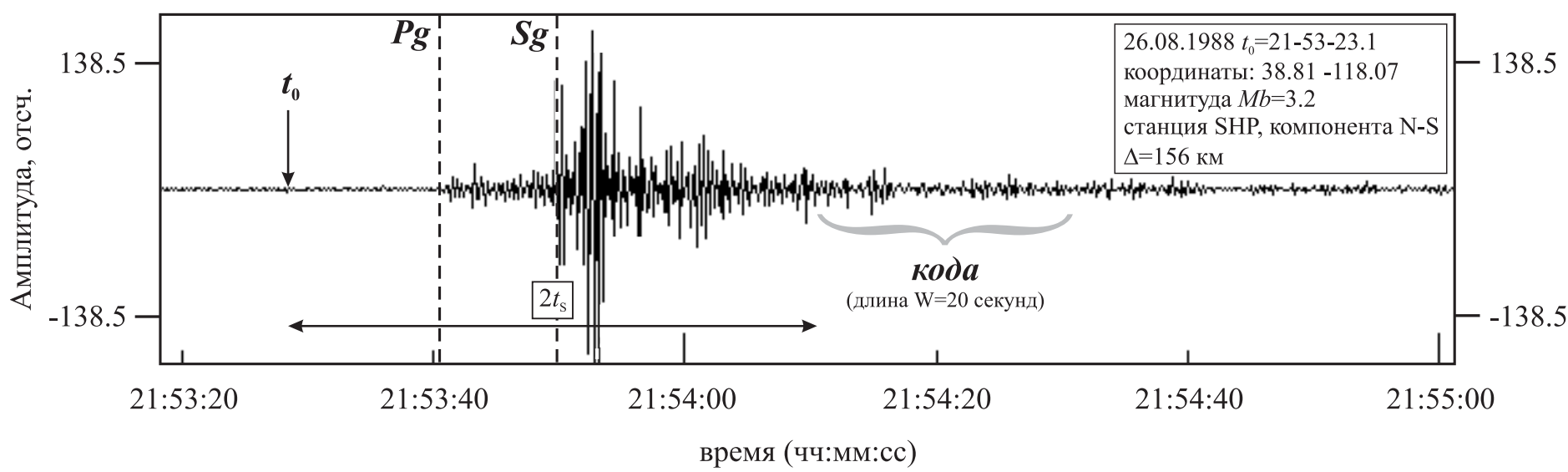

Рис. 4. Пример типичной сейсмограммы землетрясения Провинции Бассейнов и Хребтов (землетрясение 26 августа 1988 г., время в очаге $t_{0}=21-53-23.1$, магнитуда $M_{b}=3.2$ ). Сейсмограмма записана на станции SHP (Shiprock), эпицентральное расстояние $\Delta=156$ км, компонента N-S. Запись отфильтрована пропускающим фильтром с полосой 1-5 Гц. Стрелкой показано время в очаге, пунктирными линиями - вступления P- и S-волн соответственно. Скобкой показан участок коды от момента времени, равного удвоенному времени пробега $S$ волны.

Fig. 4. A typical seismogram of an earthquake in the Basin and Range Province (26 August 1988 earthquake - focal time $t_{0}=21-53-23.1$, magnitude $M_{b}=3.2$ ). The seismogram was recorded at Shiprock Station (SHP), epicentral distance $\Delta=156 \mathrm{~km}, \mathrm{~N}-\mathrm{S}$ component. The record was processed by the bandpass filter for the band of $1-5 \mathrm{~Hz}$. The arrow indicates the focal time. Dashed lines mark the arrivals of P-and S-waves, respectively. The bracket shows the coda's segment from the time equal to two travel times of S-wave. 


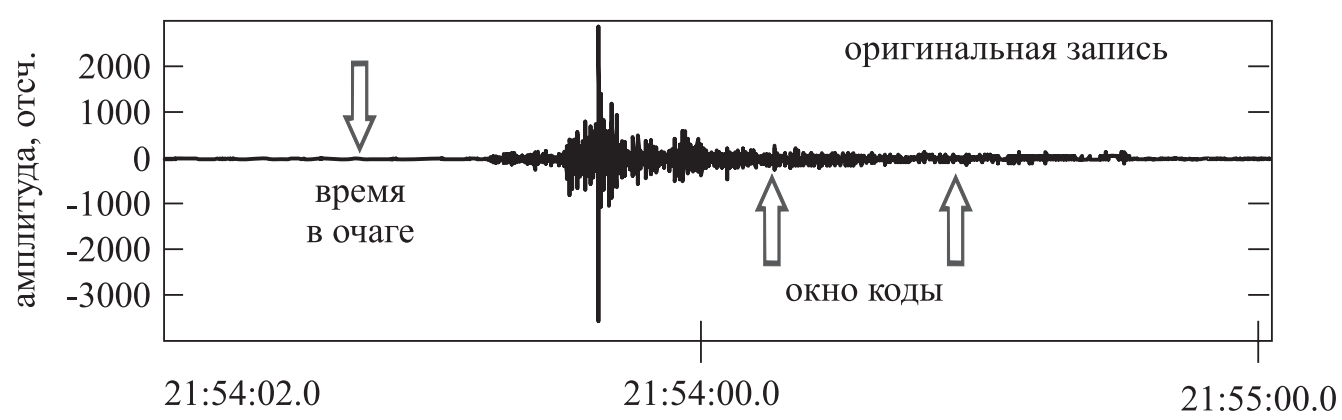

время (чч:мм:сс.с)

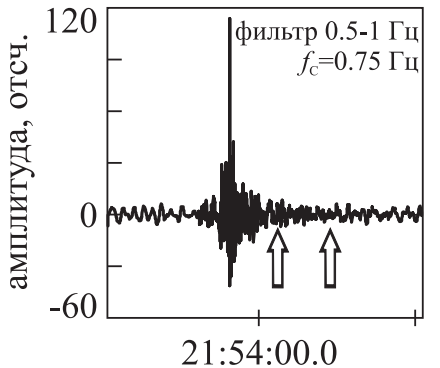

время (чч:мм:сc.с)
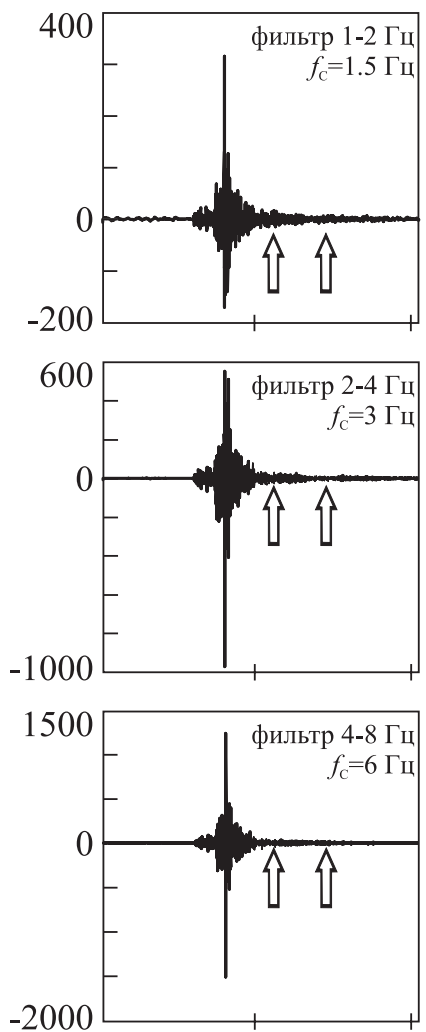
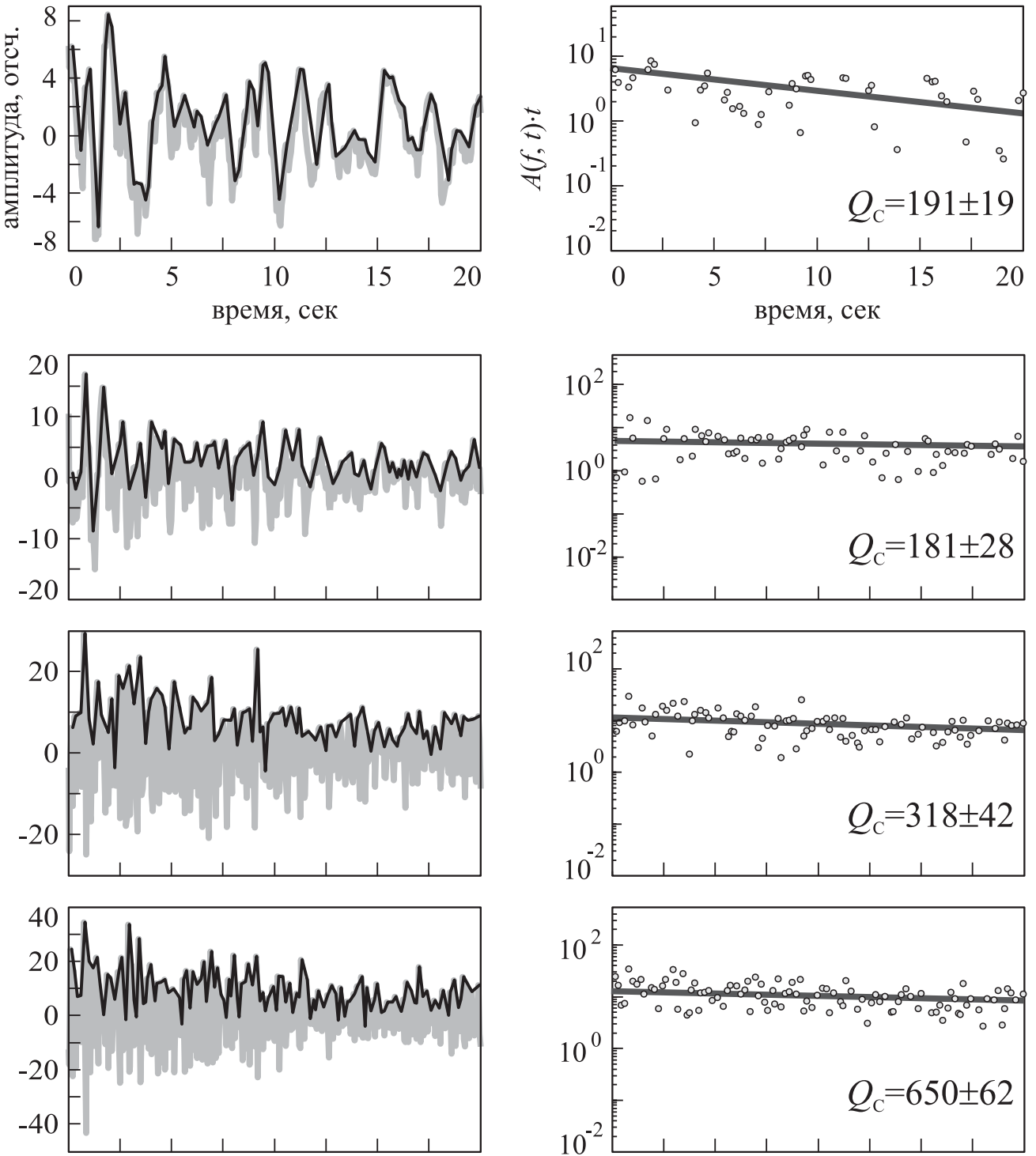

Рис. 5. Пример обработки коды для расчета сейсмической добротности $Q_{\mathrm{C}}$. Вверху показана исходная (нефильтрованная) сейсмограмма землетрясения 26 августа 1988 г. (время в очаге $t_{0}=21-53-23.1$, магнитуда $M_{b}=3.2$ ), полученная на станции NYC (New York Canyon), эпицентральное расстояние $\Delta=138$ км, компонента N-S. Стрелками показано время в очаге и анализируемый участок коды. Внизу слева показаны фильтрованные сейсмограммы (частоты пропускания 0.5-1.0, 1.0-2.0, 2.0-4.0 и 4.0-8.0 Гц соответственно). Посередине приведены фильтрованные участки коды, выбранные для расчета $Q_{\mathrm{C}}$ (длина окна 20 с), серым цветом показана отфильтрованная сейсмограмма, черным - огибающая, построенная по пиковым амплитудам. Справа представлены графики зависимости амплитуды кода-волны $A(f, t)$ от времени $t$, соответствующие регрессионные прямые, полученные с помощью MHK, и рассчитанные значения $Q_{\mathrm{C}}$.

Fig. 5. An example of coda processing for $Q_{C}$ calculations. Top - the original (non-filtered) seismogram of 26 August 1988 earthquake (focal time $t_{0}=21-53-23.1$, magnitude $M_{b}=3.2$ ); it was recorded at the New York Canyon Station (NYC); epicentral distance $\Delta=138 \mathrm{~km}$, N-S component. Arrows show the time in the focus and the analyzed segment of the coda. Bottom left - filtered seismograms (band frequency - 0.5-1.0, 1.0-2.0, 2.0-4.0, and 4.0-8.0 Hz, respectively). Middle - filtered coda's segments selected to calculate $Q_{\mathrm{C}}$ (lapse time window of 20 sec); the filtered seismogram is shown in grey, the envelope based on peak amplitudes is shown in black. Right - amplitudes of coda-wave $A(f$, $t)$ versus time, $t$, corresponding regression lines obtained by Ordinary Least Squares (OLS), and calculated values of $Q_{\mathrm{C}}$. 


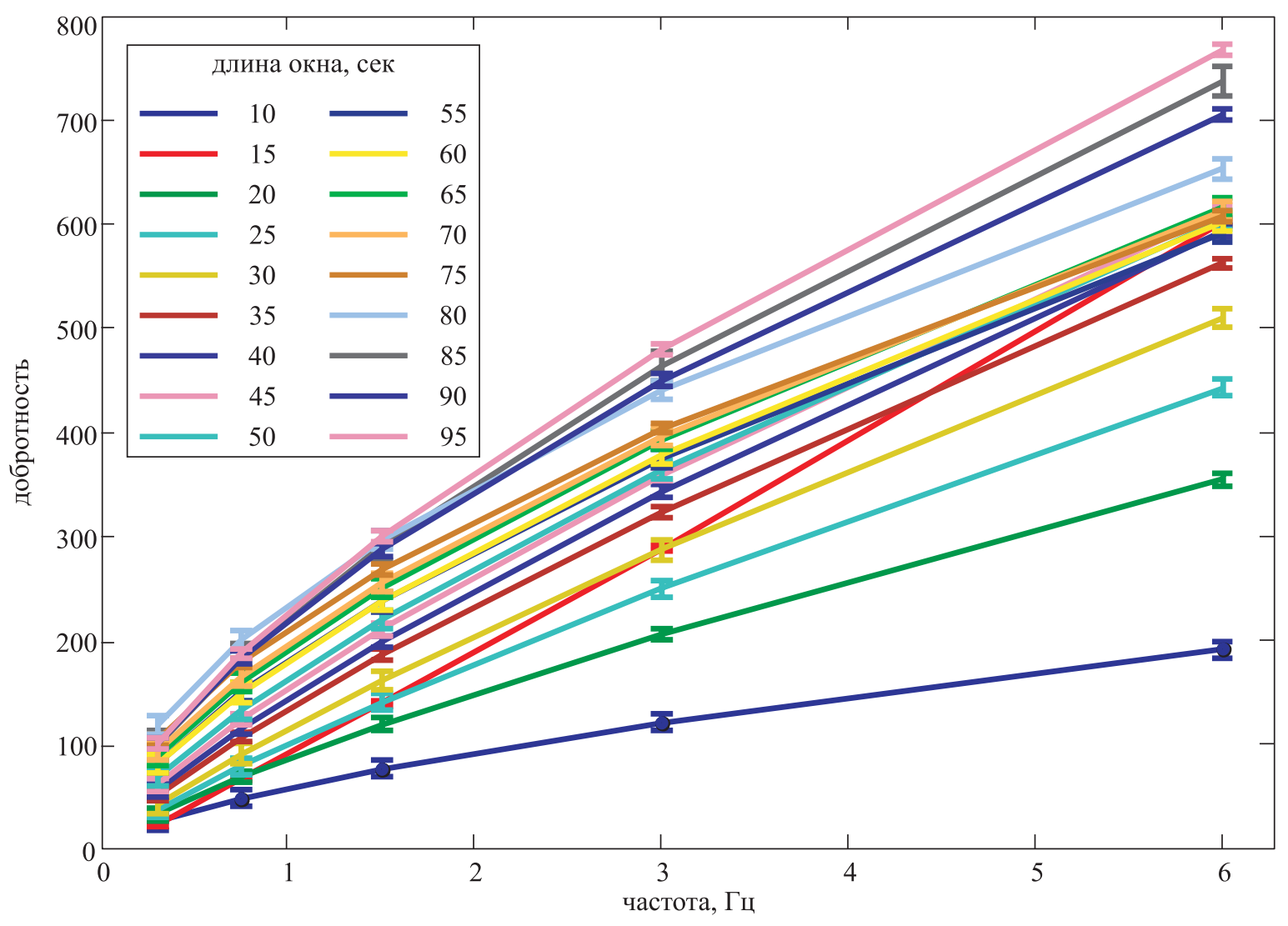

Рис. 6. Зависимость добротности от частоты для разных значений длины окна обработки коды.

Fig. 6. The dependence of the quality factor from the frequency for different lapse time windows.

гиону в зависимости от неоднородности среды [Aki, 1981]. Значения $Q_{0}$ и $n$ приведены в табл. 1.

При сопоставлении характеристик затухания сейсмических волн для различных регионов авторами работы [Mak et al., 2004] сделан вывод о том, что низкие значения добротности $(Q<200)$ наблюдаются для тектонически активных регионов мира, высокие $(Q>600)$ - для стабильных областей и промежуточные значения $(Q \approx 200-600)$ - для районов с умеренной тектонической активностью. Показатель зависимости добротности от частоты $n$ (или частотный параметр) в уравнении (4) также характеризует среду и увеличивается с интенсивностью тектонической активности региона [Aki, 1980]. При этом значения частотного параметра варьируются от $n<0.5$ для стабильных регионов до $n \approx 0.3-0.8$ для областей с умеренной тектонической активностью и $n>0.8$ для тектонически активных регионов [Mak et al., 2004].

Полученные в настоящей работе значения $Q_{0}$ меняются от $60 \pm 8$ до $222 \pm 17$, а частотного параметра - от $0.57 \pm 0.04$ до $0.84 \pm 0.05$ в зависимости от длины окна $W$ (табл. 1). Такие величины параметров $Q_{0}$ и $n$ характерны для районов с высокой тектонической активностью [Mak et al., 2004]. Рассчитанные значения добротности и частотного параметра для больших значений длины окна хорошо согласуются с данными, полученными другими авторами для Провинции Бассейнов и Хребтов по поверхностным Lg-волнам $\left(Q_{L q}\right)$ и их коде $\left(Q^{\mathrm{C}}{ }_{\mathrm{L} q}\right)$ [Singh, Herrmann, 1983; Chavez, Priestley, 1986; Xie, Mitchell, 1990; Benz et al., 1997; Baqer, Mitchell, 1998; Erickson et al., 2004; Aleqabi, Wysession, 2006] (рис. 7 , табл. 2). Также хорошее согласие наблюдается между данными, полученными в настоящей работе для Провинции Бассейнов и Хребтов и определенными автором ранее для Байкальской и Кенийской рифтовых систем: для Байкальского рифта $Q_{0}$ меняется в пределах от $103 \pm 9$ до $325 \pm 25$, параметр $n-$ от $0.89 \pm 0.06$ до $0.81 \pm 0.06$ и для Кенийского рифта $Q_{0}-$ от $74 \pm 3$ до $278 \pm 48, n$ - от $1.12 \pm 0.02$ до $0.93 \pm 0.11$ ( $W$ равна 20 и 80 с соответственно) [Dobrynina, 2011; Dobrynina et al., 2011, 2012].

Помимо расчета эффективной сейсмической добротности и ее частотной зависимости для каждого значения $W$ были получены коэффициенты затухания $\delta$ (см. табл. 1):

$$
\delta=\frac{\pi \cdot f}{V \cdot Q}
$$

здесь $V$ - скорость кода-волн, берется равной скорости 
$\mathrm{T}$ а б л и ц а 1 . Значения сейсмической добротности $Q_{0}$, частотного параметра $n$ и коэффициента затухания $\delta$ для разных значений длины окна

$\mathrm{T}$ a b l e 1 . Values of seismic quality factor $Q_{0}$, frequency parameter $n$ and attenuation coefficient $\delta$ for various lapse time windows

\begin{tabular}{|c|c|c|c|c|c|c|}
\hline$W$, с & $Q_{0}$ & $\sigma Q_{0}$ & $n$ & on & $N$ & $\delta, \mathrm{KM}^{-1}$ \\
\hline 1 & 2 & 3 & 4 & 5 & 6 & 7 \\
\hline 10 & 60 & 8 & 0.65 & 0.12 & 668 & 0.014 \\
\hline 15 & 67 & 3 & 0.84 & 0.05 & 654 & 0.012 \\
\hline 20 & 88 & 6 & 0.78 & 0.06 & 725 & 0.009 \\
\hline 25 & 100 & 8 & 0.83 & 0.06 & 727 & 0.008 \\
\hline 30 & 115 & 9 & 0.83 & 0.06 & 781 & 0.007 \\
\hline 35 & 134 & 5 & 0.8 & 0.03 & 756 & 0.006 \\
\hline 40 & 144 & 6 & 0.79 & 0.03 & 721 & 0.006 \\
\hline 45 & 154 & 6 & 0.77 & 0.03 & 664 & 0.006 \\
\hline 50 & 163 & 9 & 0.73 & 0.05 & 486 & 0.005 \\
\hline 55 & 181 & 9 & 0.66 & 0.04 & 391 & 0.005 \\
\hline 60 & 181 & 9 & 0.67 & 0.04 & 328 & 0.005 \\
\hline 65 & 192 & 9 & 0.65 & 0.04 & 274 & 0.005 \\
\hline 70 & 198 & 9 & 0.63 & 0.04 & 209 & 0.004 \\
\hline 75 & 211 & 5 & 0.59 & 0.02 & 157 & 0.004 \\
\hline 80 & 235 & 9 & 0.57 & 0.04 & 94 & 0.004 \\
\hline 85 & 220 & 6 & 0.65 & 0.03 & 63 & 0.004 \\
\hline 90 & 227 & 5 & 0.68 & 0.02 & 39 & 0.004 \\
\hline 95 & 222 & 17 & 0.67 & 0.08 & 39 & 0.004 \\
\hline
\end{tabular}

П р и м е ч а н и е. В графе 1 дана длина окна обработки коды $W$, с; 2,3 - значение добротности $Q_{0}$ на частоте 1 Гц и его среднеквадратичное отклонение; 4, 5 - значение частотного параметра $n$ и его среднеквадратичное отклонение; 6 - количество индивидуальных изме-

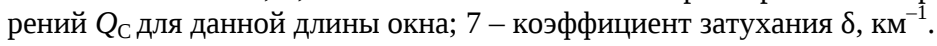

$\mathrm{N}$ o t e. Column 1 shows the lapse time window $W(\mathrm{sec}) ; 2,3$ - values of quality factor $Q_{0}$ at the frequency of $1 \mathrm{~Hz}$, and its root mean-square deviation; 4, 5 - values of frequency parameter $n$ and its root mean-square deviation; 6 - the number of individual measurements of $Q_{\mathrm{C}}$ for the given lapse time window; 7 - attenuation coefficient $\delta\left(\mathrm{KM}^{-1}\right)$.

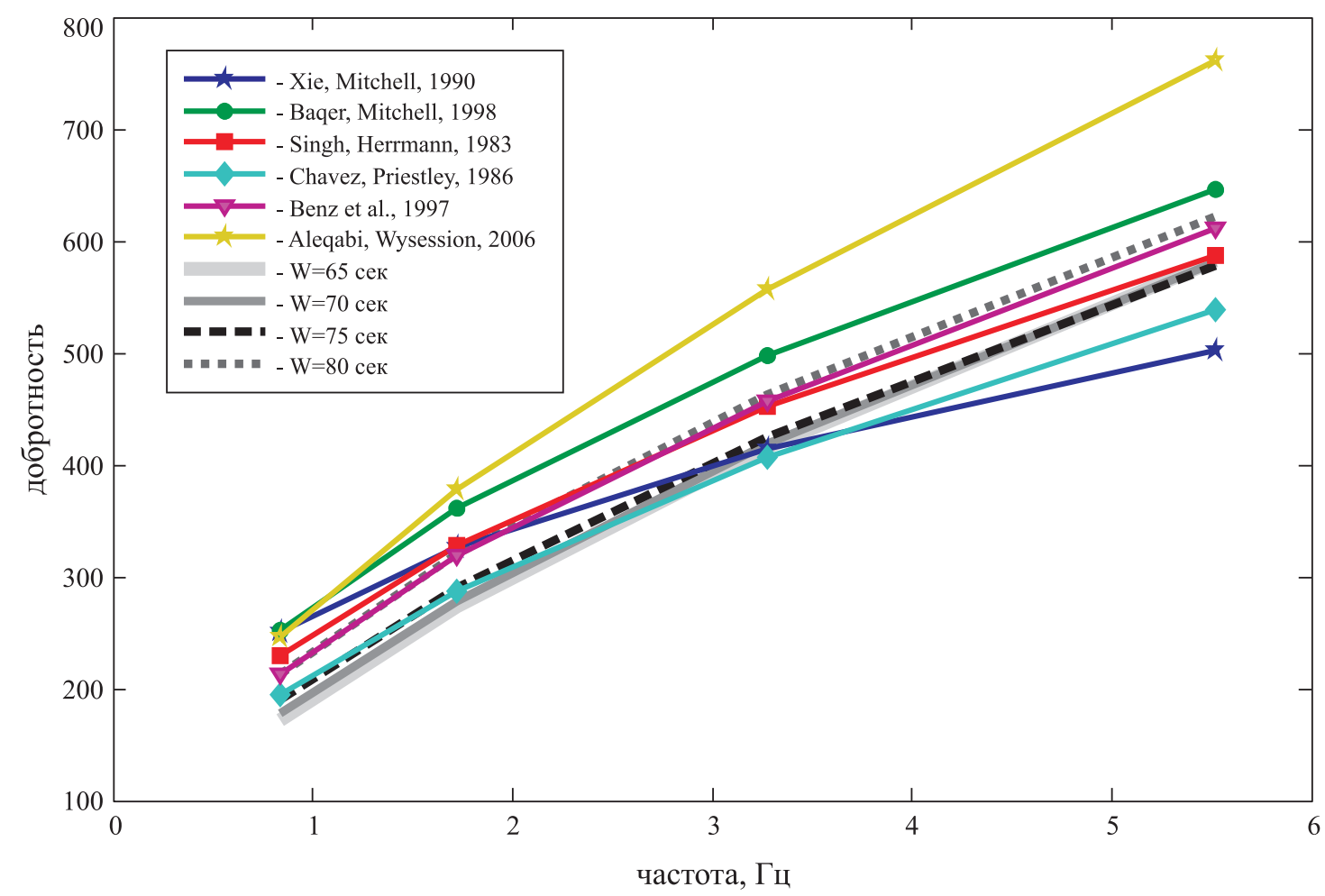

Рис. 7. Зависимости добротности от частоты для Провинции Бассейнов и Хребтов, полученные в настоящей работе и в работах предшественников.

Fig. 7. The dependence of the quality factor from the frequency for the Basin and Range Province, according to calculations in this study and those published earlier by other authors. 
A.A. Dobrynina: Attenuation of seismic waves in the lithosphere...

Т а б л и ц а 2 2. Значения $Q_{0}$ и $n$ для Провинции Бассейнов и Хребтов по результатам разных авторов

$\mathrm{T}$ a b l e 2. Values of $Q_{0}$ and $n$ for the Basin and Range Province, according to results published by other authors

\begin{tabular}{lllll}
\hline Литературный источник & $Q_{L g}$ & $Q^{\mathrm{C}}{ }_{L g}$ & $Q_{0}$ & $n$ \\
\hline 1 & 2 & 3 & $200-300$ & 5 \\
\hline Singh, Herrmann, 1983 & & & $0.40-0.60$ \\
Chavez, Priestley, 1986 & $214 \pm 15$ & $275 \pm 26$ & 0.54 \\
Xie, Mitchell, 1990 & $267 \pm 56$ & & $0.56 \pm 0.04$ \\
Benz et al., 1997 & $235 \pm 11$ & $250-300$ & $0.40-0.60$ \\
Baqer, Mitchell, 1998 & & & $234-312$ & $0.40-0.80$ \\
Erickson et al., 2004 & & & $200 \pm 77$ \\
Aleqabi, Wysession, 2006 & & & $0.69 \pm 0.16$ \\
\hline
\end{tabular}

П р и м е ч а н и е. В графе 1 дана ссылка на литературный источник; 2, 3 - значения эффективной сейсмической добротности по поверхностным $L g$ волнам и коде; 4 - значение добротности на частоте 1 Гц; 5 - частотный параметр.

$\mathrm{N}$ o t e. Column 1 gives references to publications; 2, 3 - values of the effective seismic quality factor for surface $L g$ waves and the coda; 4 - the quality factor at the frequency of $1 \mathrm{~Hz} ; 5$ - frequency parameter.

прямых поперечных волн; скорость поперечных волн в коре равна $3.4 \mathrm{kм} / \mathrm{c}$, в литосфере - $4.2 \mathrm{KM} / \mathrm{c} \mathrm{согласно}$ [Bensen et al., 2009; Shen et al., 2013].

На рис. 8 приведены вариации значений $Q_{0}$ и $n$ в зависимости от длины окна обработки коды. Видно, что за исключением небольших колебаний для малых и больших значений $W$ величина добротности на частоте
1 Гц возрастает, а частотного параметра убывает с увеличением длины окна. В рамках модели однократного рассеяния такое поведение параметров затухания может быть объяснено с позиций глубины формирования коды.

Согласно [Pulli, 1984], значение добротности, полученное для трассы «источник - приемник», характе-

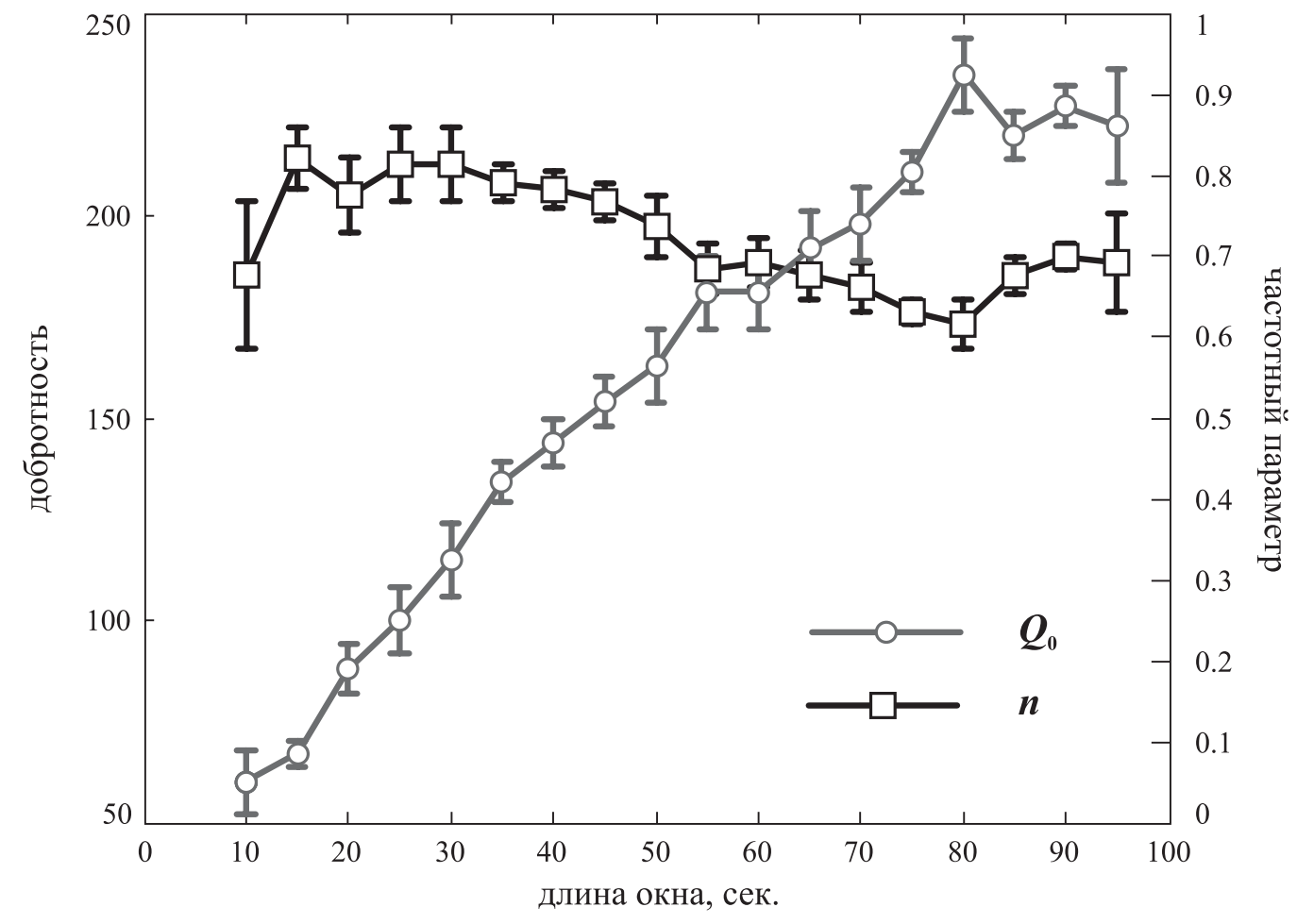

Рис. 8. Зависимость добротности $Q_{0}$ на частоте 1 Гц и частотного параметра $n$ от длины окна обработки коды $W$. Для каждого значения показано среднеквадратичное отклонение.

Fig. 8. The dependence of quality factor $Q_{0}$ at the frequency of $1 \mathrm{~Hz}$ and frequency parameter $n$ on lapse time window $W$. Root mean-square deviations are given for each value. 
Т а б л и ц а З. Двухслойная модель литосферы северной части Провинции Бассейнов и Хребтов согласно [Bensen et al., 2009; Shen et al., 2013]

$\mathrm{T}$ a b l e 3. The double-layered model of the lithosphere of the northern part of the Basin and Range Province, according to [Bensen et al., 2009; Shen et al., 2013]

\begin{tabular}{lll}
\hline Оболочка & Глубина, км & Скорость поперечных волн, км/с \\
\hline кора & $0-35$ & 3.4 \\
литосферная мантия & $>35$ & 4.2 \\
\hline
\end{tabular}

ризует некоторый объем среды (предположительно, эллипсоид), в фокусах которого расположены очаг землетрясения и сейсмическая станция. Размеры эллипсоида ( $a, b$ - длина полуосей эллипсоида, $c$ - глубина нижней границы эллипсоида) определяются следующими соотношениями:

$$
a=\frac{V t}{2} ; b=\sqrt{\left(\frac{V t}{2}\right)^{2}-\frac{r^{2}}{4}} ; c=h+\sqrt{\left(\frac{V t}{2}\right)^{2}-\frac{r^{2}}{4}},
$$

где $V$ - скорость объемных волн, $r$ - расстояние «источник - приемник», $h$ - глубина очага землетрясения, $t$ - средняя длина временного окна, которая определяется как:

$$
t=t_{\text {start }}+\frac{W}{2}
$$

где $t_{\text {start }}$ - начальное время для окна обработки коды. Следовательно, размеры исследуемой области зависят, во-первых, от длины окна обработки коды и, вовторых, от расстояния «источник - приемник». Таким образом, меняя длину окна $W$, можно проследить характер изменения $Q(f)$ с глубиной. Другими словами, увеличение добротности $Q_{\text {с }}$ с увеличением длины окна может быть интерпретировано как увеличение добротности с глубиной, так как волны, прибывающие на сейсмограмме позже, могут быть отражены от более глубоких частей литосферы, чем волны, прибывающие раньше.

Для рассматриваемых событий среднее расстояние $r$ равно $140 \mathrm{KM}$, среднее значение $t_{\text {start }}=50 \mathrm{c}$, а значения глубин землетрясений брались равными 3 км согласно [Owens, Randall, 1989]. При расчете объема эллипсоида использовались две модели: однослойная модель среды с постоянной скоростью сейсмических волн $(V=3.8 \mathrm{kM} / \mathrm{c})$ и двухслойная модель (табл. 3).

В табл. 4 приведены значения осей эллипсоида для обеих рассматриваемых моделей. Видно, что размеры эллипсоида меняются незначительно - в среднем на

Т а б л и ц а 4. Размеры области формирования коды для разных значений длины окна обработки коды для однослойной и двухслойной моделей

\begin{tabular}{|c|c|c|c|c|c|c|}
\hline \multirow[t]{2}{*}{$W, \mathrm{c}$} & \multicolumn{3}{|c|}{ Однослойная модель } & \multicolumn{3}{|c|}{ Двухслойная модель } \\
\hline & $a$, км & $b, \mathrm{KM}$ & $c$, км & $a, \mathrm{KM}$ & $b, \mathrm{KM}$ & $c, \mathrm{KM}$ \\
\hline 1 & 2 & 3 & 4 & 5 & 6 & 7 \\
\hline 10 & 115 & 134 & 118 & 102 & 124 & 105 \\
\hline 15 & 121 & 140 & 124 & 108 & 128 & 111 \\
\hline 20 & 127 & 145 & 130 & 113 & 133 & 116 \\
\hline 25 & 133 & 150 & 136 & 119 & 138 & 122 \\
\hline 30 & 139 & 155 & 142 & 124 & 143 & 127 \\
\hline 35 & 145 & 161 & 148 & 130 & 147 & 133 \\
\hline 40 & 151 & 166 & 154 & 135 & 152 & 138 \\
\hline 45 & 156 & 171 & 159 & 140 & 157 & 143 \\
\hline 50 & 162 & 176 & 165 & 146 & 162 & 149 \\
\hline 55 & 168 & 182 & 171 & 151 & 166 & 154 \\
\hline 60 & 173 & 187 & 176 & 156 & 171 & 159 \\
\hline 65 & 179 & 192 & 182 & 161 & 176 & 164 \\
\hline 70 & 185 & 197 & 188 & 167 & 181 & 170 \\
\hline 75 & 190 & 203 & 193 & 172 & 185 & 175 \\
\hline 80 & 196 & 208 & 199 & 177 & 190 & 180 \\
\hline 85 & 201 & 213 & 204 & 182 & 195 & 185 \\
\hline 90 & 207 & 218 & 210 & 187 & 200 & 190 \\
\hline 95 & 213 & 224 & 216 & 192 & 204 & 195 \\
\hline
\end{tabular}

$\mathrm{T}$ a b l e 4. Dimensions of the area, wherein the coda is formed, for different lapse time windows for the single- and double-layered models

П р и м е ч а н и е. В графе 1 дана длина окна обработки коды; в графах 2-4 - соответствующие длины полуосей эллипсоида для однослойной модели; 5-7 - длины полуосей эллипсоида для двухслойной модели.

$\mathrm{N}$ o t e: Column 1 - lapse time window; 2-4 - corresponding lengths of semi-axes of the ellipsoid for the single-layered model; 5-7 - lengths of semi-axes of the ellipsoid for the double-layered model. 

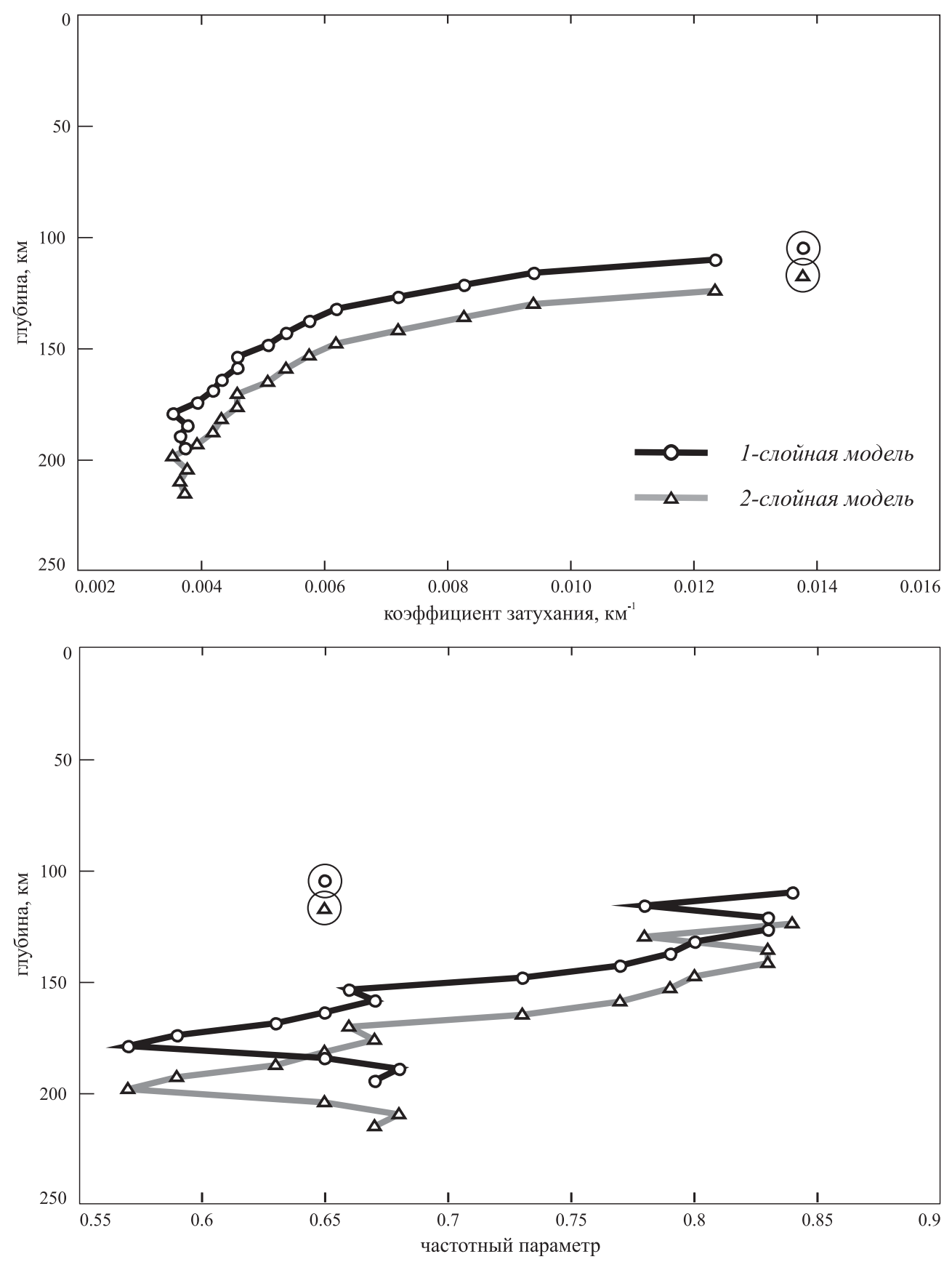

Рис. 9. Зависимость коэффициента затухания $\delta$ (вверху) и частотного параметра $n$ (внизу) от глубины. Обведены определения $\delta$ и $n$ для длины окна $W=10$ с.

Fig. 9. The dependence of attenuation coefficient $\delta$ (top) and frequency parameter $n$ (bottom) from the depth. Circles - values of $\delta$ and $n$ for the given lapse time window, $\mathrm{W}=10$ sec.

16 км. На рис. 9 показаны зависимости коэффициента затухания $\delta$ и частотного параметра $n$ от глубины для обеих используемых моделей среды. Оба параметра неравномерно уменьшаются с увеличением глубины. Видно, что на глубинах от 130 км (для однослойной модели) до 150 км (для двухслойной модели) наклон графика изменения коэффициента затухания меняется. В дальнейшем для интерпретации будет использоваться двухслойная модель. В верхней части графика (глубины до 150 км) наблюдается резкое изменение $\delta$ с глубиной (рис. 9, 10), особенно хорошо это видно на графике градиента коэффициента затухания, подобное поведение характерно и для частотного параметра. Также на глубине около 140 км отмечается скачок частотного параметра $n$. В средней части (на глубинах $150-200$ км) угол наклона графика $\delta(c)$ увеличивается (см. рис. 9), градиенты коэффициента затухания и частотного параметра значительно уменьшаются (рис. $10)$. И в нижней части разреза (>200 км) значение коэффициента затухания становится практически посто- 

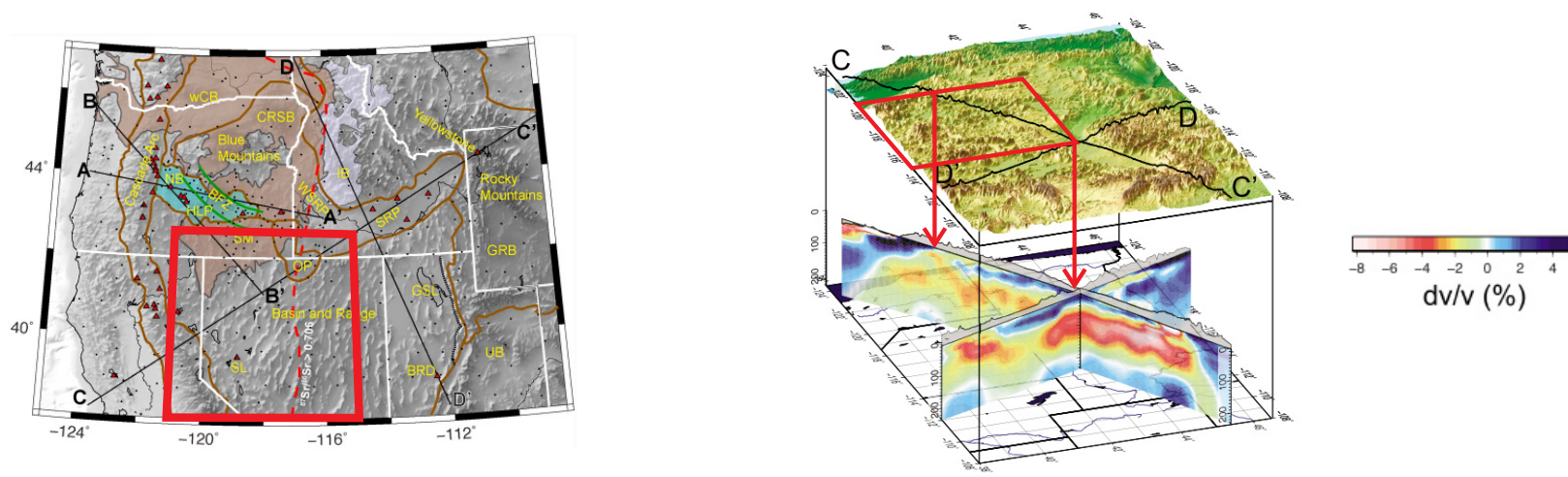

$\mathrm{dv} / \mathrm{v}(\%)$
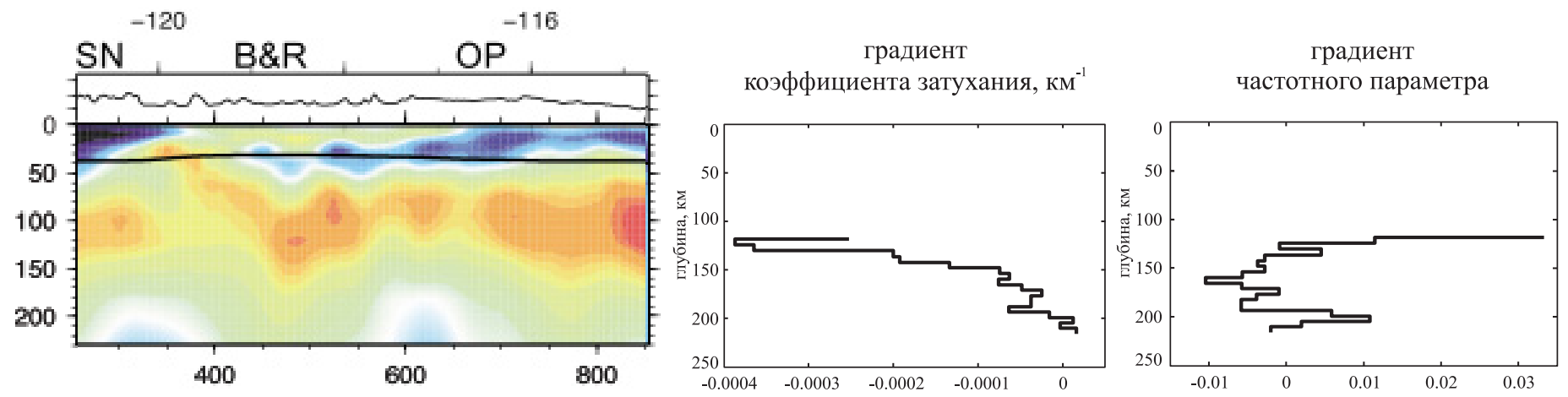

Рис. 10. Сопоставление скоростного строения Провинции Бассейнов и Хребтов и градиентов коэффициента затухания и частотного параметра. Вверху показаны карта района и блок-диаграмма скоростных аномалий северо-западного побережья Тихого океана (рисунок заимствован из работы [Wagner et al., 2012]), красным прямоугольником показан исследуемый регион. Внизу - сопоставление градиентов коэффициента затухания и частотного параметра и глубинного строения Провинции Бассейнов и Хребтов. Черной линией показана граница Мохо.

Fig. 10. Comparison of the velocity structure of the Basin and Range Province and gradients of the attenuation coefficient and the frequency parameter. Top - the map of the area under study and the block diagram of velocity anomalies of the north-western coast of the Pacific Ocean (the figure is taken from [Wagner et al., 2012]); the red rectangle shows the area under study. Bottom - comparison of gradients of the attenuation coefficient and the frequency parameter and the deep structure of the Basin and Range Province. The black line shows the Moho.

янным, также отмечается резкое скачкообразное увеличение значения частотного параметра (см. рис. 9). На рис. 10 приведен скоростной разрез исследуемого региона, полученный в работе [Wagner et al., 2012]. На разрезе видно, что под Провинцией Бассейнов и Хребтов расположена низкоскоростная мантийная аномалия, начинающаяся практически под границей Мохо (на глубине 50-60 км). Нижняя граница аномальной мантии находится на глубине 130-160 км. Подобное поведение коэффициента затухания и частотного параметра с глубиной ранее было отмечено автором при исследовании характеристик затухания в литосфере и верхней мантии Байкальского и Кенийского рифтов [Dobrynina, 2011; Dobrynina et al., 2011, 2012].

Таким образом, можно заключить, что изменение угла наклона графика зависимости коэффициента затухания от глубины для Провинции Бассейнов и Хребтов связано со скоростным строением среды. При этом резкие изменения коэффициента затухания и частотного параметра приурочены к границам аномальной и нормальной мантии. Высокие значения затухания и частотного параметра, характерные для верхней части разреза, свидетельствуют о высокой степени неоднородности среды, что подтверждается также низкими скоростями сейсмических волн в данной области (рис. 10) [Wagner et al., 2012]. Уменьшение параметров $\delta$ и $n$ в средней и нижней частях разреза говорит о более однородной структуре среды на больших глубинах.

\section{6. ЗАКЛЮЧЕНИЕ}

В настоящей работе была сделана попытка оценить затухание сейсмических волн в литосфере и верхней мантии северной части Провинции Бассейнов и Хребтов на основе анализа кода-волн 66 локальных землетрясений и взрывов. В результате для Провинции Бассейнов и Хребтов получены значения эффективной сейсмической добротности $Q_{\mathrm{C}}$, частотного параметра $n$ и коэффициента затухания $\delta$. Значения эффективной

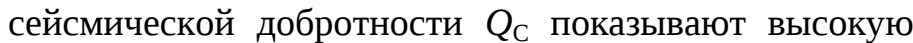
зависимость от частоты в диапазоне 0.5-16.0 Гц. Рассчитаны эмпирические соотношения $Q(f)$ для разной длины окна обработки коды - от 10 до 95 с. Показано, 
что значение эффективной сейсмической добротности

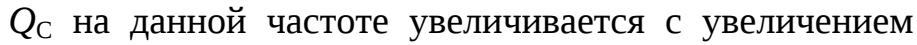
длины окна обработки коды, что может быть интерпретировано как проявление уменьшения затухания с глубиной. Сопоставление глубинных вариаций коэффициента затухания $\delta$ и частотного параметра $n$ со скоростным строением региона показало, что для Провинции Бассейнов и Хребтов наблюдается отчетливое изменение поведения затухания сейсмических волн на скоростных границах. Сравнение полученных характеристик затухания с аналогичными параметрами, рассчитанными автором ранее для Байкальского и Кенийского рифтов, показало хорошую согласованность ре- зультатов, что может свидетельствовать о сопоставимых по уровню процессах модификации литосферы в разных рифтовых зонах.

\section{7. БЛАГОДАРНОСТИ}

Исследование выполнено при финансовой поддержке РФФИ в рамках научного проекта № 12-0531038_мол-а. Автор выражает благодарность рецензентам д.т.н. А.Ф. Еманову и к.г.-м.н. В.В. Чечельницкому за конструктивные замечания и предложения, способствовавшие улучшению статьи.

\section{8. ЛИТЕРАТУРА}

Aki K., 1969. Analysis of the seismic coda of local earthquakes as scattered waves. Journal of Geophysical Research 74 (2), 615-631. http://dx.doi.org/10.1029/JB074i002p00615.

Aki K., 1980. Attenuation of shear-waves in the lithosphere for frequencies from 0.05 to $25 \mathrm{~Hz}$. Physics of the Earth and Planetary Interiors 21 (1), 50-60. http://dx.doi.org/10.1016/0031-9201(80)90019-9.

Aki K., 1981. Source and scattering effects on the spectra of small local earthquakes. Bulletin of the Seismological Society of America 71 (6), 1687-1700.

Aki K., Chouet B., 1975. Origin of the coda waves: source, attenuation and scattering effects. Journal of Geophysical Research 80 (23), 3322-3342. http://dx.doi.org/10.1029/JB080i023p03322.

Aleqabi G.I., Wysession M.E., 2006. Distribution Q Lg in the Basin and Range Province of the Western United States. Bulletin of the Seismological Society of America 96 (1), 348-354. http://dx.doi.org/10.1785/0120040086.

Baqer S., Mitchell B.J., 1998. Regional variation of Lg coda Q in the continental United States and its relation to crustal structure and evolution. Pure and Applied Geophysics 153 (2-4), 613-638. http://dx.doi.org/10.1007/s000240050210.

Bensen G.D., Ritzwoller M.H., Yang Y., 2009. A 3-D shear velocity model of the crust and uppermost mantle beneath the United States from ambient seismic noise. Geophysical Journal International 177 (3), 1177-1196. http://dx.doi.org/10. 1111/j.1365-246X.2009.04125.x.

Benz H., Frankel A., Boore D., 1997. Regional Lg attenuation of the continental United States. Bulletin of the Seismological Society of America 87 (3), 606-619.

Burger R.W., Somerville P.G., Barker J.S., Herrmann R.B, Helmberger D.V., 1987. The effect of crustal structure on strong ground motion attenuation relations in eastern North America. Bulletin of the Seismological Society of America 77 (2), 420-439.

Chavez D., Priestley K., 1986. Measurement of frequency dependent Lg attenuation in the Great Basin. Geophysical Research Letters 13 (6), 551-554. http://dx.doi.org/10.1029/GL013i006p00551.

Dobrynina A.A., 2011. Coda-wave attenuation in the Baikal rift system lithosphere. Physics of the Earth and Planetary Interiors 188 (1-2), 121-126. http://dx.doi.org/10.1016/j.pepi.2011.05.008.

Dobrynina A.A., Albaric J., Deschamps A., Perrot J., Ferdinand R.W., Deverchere J., Sankov V.A., Chechelnitsky V.V., 2012. Seismic waves attenuation in continental lithosphere under extensional condition: comparison of the East African and Baikal rift systems. In: Book of abstracts 33rd General Assembly of the European Seismological Commission (GA ESC 2012), 19-24 August 2012, Moscow and Young Seismologist Training Course (YSTC 2012), 25-30 August 2012, PH "Poligrafiqwik”, Obninsk, p. 32-33.

Dobrynina A.A., San'kov V.A., Chechel'nitskii V.V., 2011. Seismic quality factor of the lithosphere of the southwestern flank of the Baikal rift system. Russian Geology and Geophysics 52 (5), 555-564. http://dx.doi.org/10.1016/j.rgg.2011.04.008.

Erickson D., McNamara D.E., Benz H.M., 2004. Frequency-Dependent Lg Q within the Continental United States. Bulletin of the Seismological Society of America 94 (5), 1630-1643. http://dx.doi.org/10.1785/012003218.

Havskov J., Ottemoller L., 2003. SEISAN: The Earthquake Analysis Softwares for Windows, Solaris and Linux, Version 8.0. Institute of Solid Earth Physics, University of Bergen, Norway. 348 p. http://www.geo.uib.no/seismo/software/software. html.

Lay T., Wallace T.C., 1988. Multiple ScS attenuation and travel times beneath western North America. Bulletin of the Seismological Society of America 78 (6), 2041-2061.

Lee J., Garwood J., Stockli D.F., Gosse J., 2009. Quaternary faulting in Queen Valley, California-Nevada: Implications for kinematics of fault slip transfer in the Eastern California Shear Zone-Walker Lane Belt. The Geological Society of Ame- 
rica Bulletin 121 (3-4), 599-614. http://dx.doi.org/10.1130/B26352.1.

Mak S., Chan L.S., Chandler A.M., Koo R., 2004. Coda Q estimates in the Hong Kong region. Journal of Asian Earth Sciences 24 (1), 127-136. http://dx.doi.org/10.1016/j.jseaes.2003.10.001.

Mitchell B., 1981. Regional variation and frequency dependence of Qb in the crust of the United States. Bulletin of the Seismological Society of America 71 (5), 1531-1538.

Owens T.J., Randall G.E., 1989. Data report for «The 1988-89 PASSCAL Basin and Range Passive-Source Seismic Experiment. Part I: Large Aperture Array Data» for the project science team. IRIS data Management system. PASSCAL Data Report 90-001. 21 p.

Pulli J.J., 1984. Attenuation of coda waves in New England. Bulletin of the Seismological Society of America 74 (4), 1149 1166.

Rautian T.G., Khalturin V.I., 1978. The use of coda for determination of the earthquake source spectrum. Bulletin of the Seismological Society of America 68 (4), 923-948.

Ryan W.B.F., Carbotte S.M., Coplan J.O., O'Hara S., Melkonian A., Arko R., Weissel R.A., Ferrini V., Goodwillie A., Nitsche F., Bonczkowski J., Zemsky R., 2009. Global multi-resolution topography synthesis. Geochemistry, Geophysics, Geosystems 10 (3), Q03014. http://dx.doi.org/10.1029/2008GC002332.

Shen W., Ritzwoller M.H., Schulte-Pelkum V., Lin F.-C., 2013. Joint inversion of surface wave dispersion and receiver functions: A Bayesian Monte-Carlo approach. Geophysical Journal International 192 (2), 807-836. http://dx.doi.org/10.1093/ gji/ggs050.

Singh S., Herrmann R., 1983. Regionalization of crustal coda Q in the continental United States. Journal of Geophysical Research: Solid Earth 88 (B1), 527-538. http://dx.doi.org/10.1029/JB088iB01p00527.

Wagner L.S., Fouch M.J., James D.E., Hanson-Hedgecock S., 2012. Crust and upper mantle structure beneath the Pacific Northwest from joint inversions of ambient noise and earthquake data. Geochemistry, Geophysics, Geosystems 13 (12), Q0AN03. http://dx.doi.org/10.1029/2012GC004353.

Xie J.K., Mitchell B.J., 1990. Attenuation of multiphase surface waves in the Basin and Range Province, part I: Lg and Lg coda. Geophysical Journal International 102 (1), 121-137. http://dx.doi.org/10.1111/j.1365-246X.1990.tb00535.x.

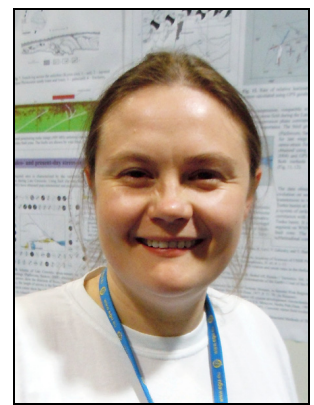

Добрынина Анна Александровна, канд. физ.-мат. наук

Институт земной коры СО РАН

664033, Иркутск, ул. Лермонтова, 128, Россия

凶e-mail: dobrynina@crust.irk.ru

Dobrynina, Anna A., Candidate of Physics and Mathematics

Institute of the Earth's Crust, Siberian Branch of RAS

128 Lermontov street, Irkutsk 664033, Russia

凶e-mail: dobrynina@crust.irk.ru 